\title{
Enhancement of mesophase formation in paraffinic-rich clarified oil using transition metal catalysts $(\mathrm{Cr}$ and $\mathrm{Cu})$
}

\author{
Subhash $\mathrm{Kumar}^{1,2} \cdot$ Manoj Srivastava ${ }^{1,2}$
}

Received: 8 May 2018 / Accepted: 26 December 2018 / Published online: 4 January 2019

(c) The Author(s) 2019

\begin{abstract}
In the present work, we have made attempts to prepare petroleum pitches from paraffinic-rich clarified oil (CLO) by giving thermal treatment at $370{ }^{\circ} \mathrm{C}$ in the presence of $\mathrm{Cu}$ and $\mathrm{Cr}$ catalysts. The feed CLO is predominantly paraffinic in nature, so it takes fairly large thermal soaking time $(21 \mathrm{~h})$ to convert into pitch having mesophase content below countable limits. To increase the mesophase content in the pitch or to make mesophase pitch, $3 \mathrm{wt} \%$ transition metal catalysts $(\mathrm{Cu}$ and $\mathrm{Cr})$ were added to CLO. Addition of transition metal catalysts not only enhances mesophase formation but also helps to reduce thermal treatment time by promoting polymerization and condensation reactions at a faster rate. The mesophase formation pattern reveals that $\mathrm{Cu}$ and $\mathrm{Cr}$ catalysts increase the mesophase content from below countable limit to 12 and 9 vol \%, respectively. This indicates that $\mathrm{Cu}$ and $\mathrm{Cr}$ showed better catalytic activity for mesophase formation growth. The effect of transition metal catalysts on physico-chemical properties (softening point, coking value, toluene insolubles and quinoline insolubles) as well as the optical texture and physical properties of mesophase pitches were investigated by optical microscope, FT-IR, SEM, NMR, TG/DTG and XRD.
\end{abstract}

Keywords Clarified oil · Transition metals · Thermal treatment · Mesophase

\section{Introduction}

Mesophase pitches are prepared either by thermal $[6,13]$ or catalytic polymerization $[18,20,22,23]$ processes from low-value petroleum and coal by-products, i.e., decant oils. These pitches are complex mixtures of various types of organic molecules that mainly consist of polycyclic aromatic hydrocarbons (PAH). Furthermore, this mesophase pitch is very cheap and readily available, and has attracted extensive attention as promising materials for a variety of applications, such as needle coke [24], carbon fibers [36], Li-ion battery cathode [34], C-C composites [16], carbon foam [14], activated carbon [1], mesocarbon microbeads [35], etc.

In previous reported literature $[4,19,21,25,28]$, many researchers prepared mesophase pitches from petroleum residues, coal tar pitches and pure aromatic compounds using

Subhash Kumar

dangwalx75@gmail.com

1 Academy of Scientific and Innovative Research (AcSIR), CSIR-Indian Institute of Petroleum, Dehradun 248005, India

2 Heavy Oil Processing Area, CSIR-Indian Institute of Petroleum, Dehradun 248005, India
Lewis acid. $\mathrm{AlCl}_{3}$ and $\mathrm{HF} / \mathrm{BF}_{3}$ are extensively used catalysts to prepare spinnable mesophase pitch from aromatic hydrocarbons. Among these, $\mathrm{AlCl}_{3}$ was not completely recovered from resulting pitch, whereas $\mathrm{HF} / \mathrm{BF}_{3}$ was easily recovered. Most of the previous works on catalyzing mesophase formation have focused on either minimizing the impact of the retained catalyst or on recovering the catalyst from the product. In our previous paper [9], we have used cobalt and nickel salts in petroleum residues (paraffinic clarified oil and aromatic heavy extract) to enhance the mesophase contents, pitch yields and other physico-chemical properties. Among these petroleum residue paraffinic clarified oil having very low bureau of mines correlation index (BMCI), i.e., 51 is produced a pitch contained mesophase contents below countable limit and pitch yield being quite low (11.88 $\mathrm{wt} \%$ ). Although, the presence of transition metal salts (Co and $\mathrm{Ni}$ ) in paraffinic clarified oil enlarged the size of mesophase spheres, i.e., increased the mesophase contents, pitch yield and other physico-chemical properties. Here, the recovery of catalysts has done by refluxing higher-density part of pitch which was settled down bottom of the reactor with ethanol. As we know that mesophase pitches are used as a precursor material for premium-quality petroleum coke. 
This premium-quality petroleum coke is used for making graphite electrode for steel industries. Most of the premiumquality petroleum coke in India is imported from foreign countries for making graphite electrode and other carbon products. Keeping this in view, we are trying to explore different types of transition metal catalysts which enhance the mesophase formation in paraffinic clarified oil. This study will help petroleum refiners for production of mesophase pitch/premium-quality petroleum coke.

In the present work, we have made attempts to prepare petroleum pitches by the aid of $\mathrm{Cr}$ and $\mathrm{Cu}$ salts into paraffinic-rich clarified oil (CLO) obtained from fluidized catalytic cracking (FCC) process in petroleum refinery by giving thermal treatment at $370{ }^{\circ} \mathrm{C}$. Pitches of different thermal soaking time are observed to examine the poly-condensation and mesophase transformation in the presence of different catalysts. Furthermore, synthesized mesophase pitches was also studied by applying several instrumental techniques such as FT-IR, NMR, XRD, TG/DTG, scanning electron microscopy (SEM) combined with energy dispersive X-ray spectroscopy (EDX), optical microscopic imaging, etc.

\section{Experimental section}

\section{Raw materials}

In this study, petroleum-derived clarified oil (CLO) from Indian petroleum refinery (Hindustan Petroleum Corporation Limited, Mumbai) was used as the precursor for mesophase pitches and its physico-chemical properties are reported in our previous paper [9]. $\mathrm{CuCl}_{2} \cdot 4 \mathrm{H}_{2} \mathrm{O}$ (99\%, Acros Organics) and anhydrous $\mathrm{CrCl}_{3}(99 \%$, Acros Organics) were chosen as the catalysts. AR grade toluene (99.5\%, Loba Chemie), and quinoline (97\%, Merck Chemicals), were used as solvents for determining insolubility in mesophase pitches.

\section{Preparation of mesophase pitches}

A mixture of $170 \mathrm{~g}$ clarified oil (CLO) and $3 \mathrm{wt} \%$ (all concentrations are expressed in weight percentage of total reaction mixture) catalysts $(\mathrm{Cr}$ and $\mathrm{Cu}$ salts) was agitated at $150{ }^{\circ} \mathrm{C}$ for $1 \mathrm{~h}$ and placed in a glass reactor. Thermal treatment of the mixtures was carried out with the help of heating mantle at temperature $370{ }^{\circ} \mathrm{C}$ under a nitrogen flow at atmospheric pressure at a heating rate of $5{ }^{\circ} \mathrm{C} / \mathrm{min}$. The nitrogen gas flow rate was about $150 \mathrm{ml} / \mathrm{min}$ for $170 \mathrm{~g}$ of feed using wet gas flow meter to provide enough turbulence in viscous pitch. The resultant mesophase pitches prepared from CLO were named as CLO-Cr-3 and CLO-Cu-3. In the pitch nomenclature, first value denotes feed stock, second denotes transition metal catalyst and third denotes wt $\%$ of catalyst. The physico-chemical properties of all synthesized mesophase pitches are given in Table 1. A schematic process for making mesophase pitches from clarified oil using transition metal salts $(\mathrm{Cr}$ and $\mathrm{Cu})$ is represented in Fig. 1.

\section{Characterization of mesophase pitches}

Softening point, coking value, toluene insolubles and quinoline insolubles of mesophase pitches are determined by American Society for Testing Materials (ASTM) test procedures, i.e., ASTM D-3104, ASTM D-4530, ASTM D-4312 and ASTM D-2318, respectively.

Elemental analyses (carbon, hydrogen, nitrogen and sulphur contents) of the mesophase pitch samples were determined using Elemental Vario Micro Cube instrument.

The microstructures of mesophase pitches were studied with optical microscopy (OM) under polarized light
Table 1 Physico-chemical properties of pitches

\begin{tabular}{llllll}
\hline Characteristics & CLO-0-0 [9] & CLO-Co-3 [9] & CLO-Ni-3 [9] & CLO-Cr-3 & CLO-Cu-3 \\
\hline Thermal soaking time (h) & 21.00 & 7.30 & 2.20 & 4.20 & 5.35 \\
$\mathrm{PY}^{\mathrm{a}}$ (wt \%) & 11.88 & 16.22 & 15.08 & 17.42 & 18.16 \\
$\mathrm{MC}^{\mathrm{b}}($ vol \%) & $\mathrm{BCL}^{\mathrm{g}}$ & 16 & 13 & 9 & 12 \\
$\mathrm{SP}^{\mathrm{c}}\left({ }^{\circ} \mathrm{C}\right)$ & 98 & 126 & 125 & 145 & 120 \\
$\mathrm{CV}^{\mathrm{d}}($ wt \%) & 48.97 & 56.69 & 55.44 & 57.30 & 54.96 \\
$\mathrm{TI}^{\mathrm{e}}($ wt \%) & 20.39 & 36.66 & 36.69 & 51.64 & 36.15 \\
$\mathrm{QI}^{\mathrm{f}}($ wt \%) & 1.08 & 5.00 & 4.93 & 26.35 & 5.51 \\
\hline
\end{tabular}

${ }^{\text {a } P i t c h ~ y i e l d ~}$

${ }^{\mathrm{b}}$ Mesophase contents

${ }^{\mathrm{c}}$ Softening point

${ }^{\mathrm{d}}$ Coking value

eToluene insolubles

${ }^{\mathrm{f}}$ Quinoline insolubles

${ }^{\mathrm{g}}$ Below countable limit 


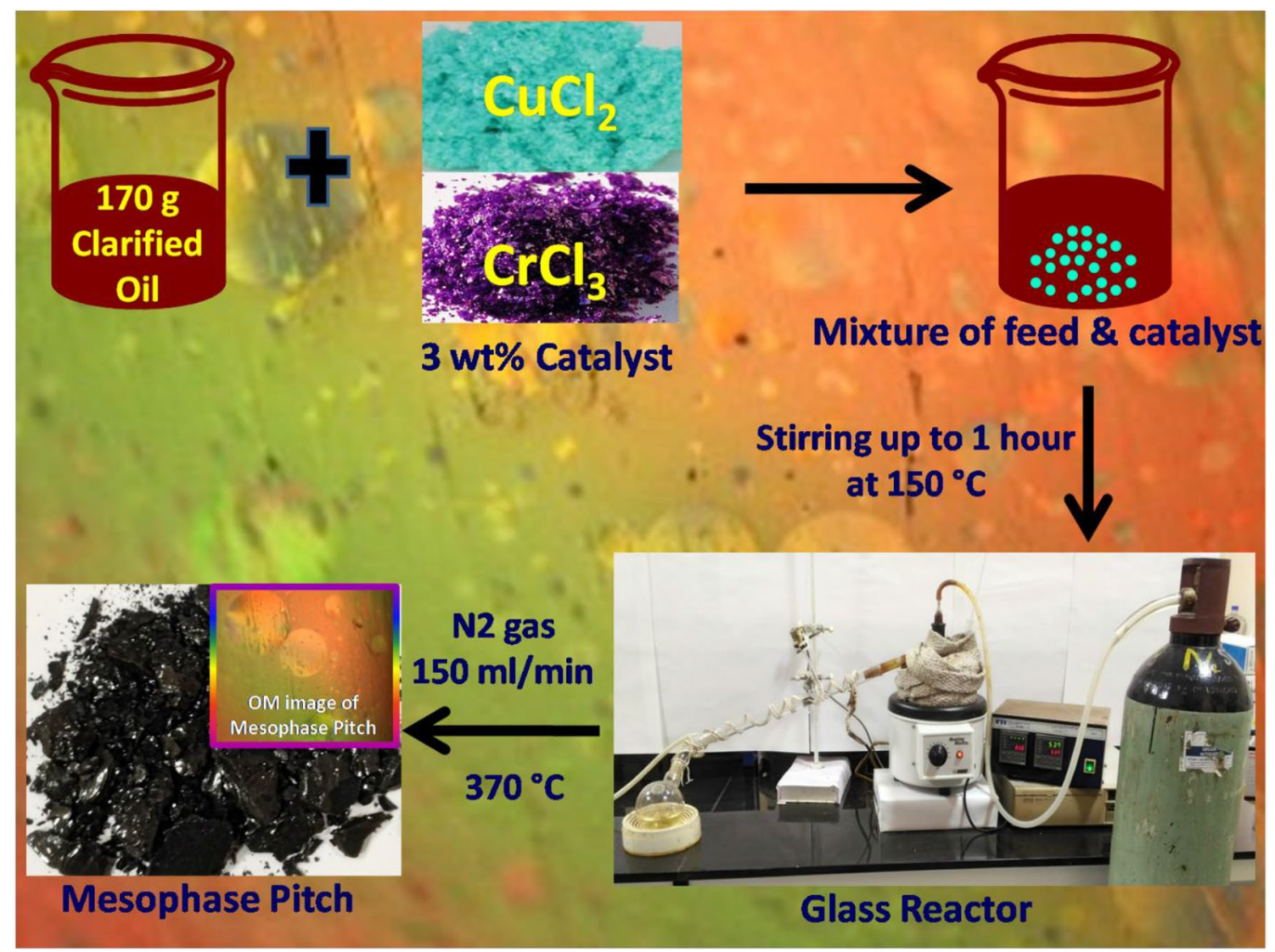

Fig. 1 Schematic diagram of experimental process for making mesophase pitch

(NIKON optical microscope). To determine mesophase contents (MC) in different mesophase pitch samples, ASTM D 4616-95 test procedure was used.

Mesophase pitches were analyzed by FT-IR, using a Perkin-Elmer spectrometer over the range of $4000-500 \mathrm{~cm}^{-1}$. $\mathrm{The} \mathrm{KBr}$ pellet technique was used in this analysis.

The mesophase pitch samples were characterized by liquid-state ${ }^{1} \mathrm{H}$ NMR and ${ }^{13} \mathrm{C}$ NMR spectroscopy. The analyses of these samples were performed with a Bruker AV-III 500 NMR spectrometer with ${ }^{1} \mathrm{H}$ Larmor frequency of $500.1 \mathrm{MHz}$. For ${ }^{1} \mathrm{H}$ NMR and ${ }^{13} \mathrm{C}$ NMR spectroscopic analyses, solutions of pitches were made in $\mathrm{CDCl}_{3}$ and tetramethyl-silane (TMS) was used as an 'internal reference'. For ${ }^{1} \mathrm{H}$ NMR analysis, a solution of $10 \mathrm{wt} \%$ of the sample was prepared in $\mathrm{CDCl}_{3}$; while for ${ }^{13} \mathrm{C}$ NMR analysis, concentration of sample was increased to about to $40 \mathrm{wt} \%$.

$\mathrm{X}$-ray diffraction was performed on mesophase pitch samples D8 Advance Diffractometer, Bruker, Germany. The radiation used was the $\mathrm{K} \alpha$ line from the $\mathrm{Cu}$ $(\lambda=0.15418 \mathrm{~nm})$. Powdered pitch samples were scanned from $2-80^{\circ}$ in $2 \theta$ range with $0.02^{\circ}$ step size at a scan rate $1 \% \mathrm{~min}$. The diffractograms were used to calculate interlayer spacing $\left(d_{002}\right)$ by Bragg's equation, $2 d_{002} \sin \theta=\lambda$ [30] and crystallite thickness $\left(L_{\mathrm{c}}\right)$ by Scherrer formula, $L_{\mathrm{c}}=0.89 \lambda /$ $\left(\beta_{002} \cos \theta_{002}\right)$, where $\lambda$ is $0.15406 \mathrm{~nm}, \theta$ is the Bragg angle, and $\beta$ is the full width at half maximum [15]. From $d_{002}$ and $L_{\mathrm{c}}$ values, number of aromatic sheet in stacked cluster $(N)$ is calculated by following formula, $N=L_{\mathrm{c}} / d_{002}+1$ and average number of carbon atom per lamellae $(n)$ is calculated by following formula, $n=0.32 N^{2}$ [15].

Scanning electron microscopy (SEM) was used to analyze surface morphologies of mesophase pitch samples obtained from CLO using 'field-emission scanning electron microscope-energy dispersive spectrometer system' (ModelQuanta 200 F). The surface coating of mesophase pitch samples were done with pure 'Gold' using EMITECH Gold Sputtering unit. The image of pitch samples was taken at $500 \times$ magnification using E.T.D. detector and $30-\mathrm{kV}$ beam current for morphological study.

The thermal behavior and properties of mesophase pitches during pyrolysis were monitored by thermogravimetrical analysis. TG and DTG analyses were performed in a TA Instruments SDT 2960 thermal analyzer on $10 \mathrm{mg}$ of sample placed in thermobalance. The temperature was increased from room temperature to $900{ }^{\circ} \mathrm{C}$ at a heating rate of $10^{\circ} \mathrm{C} \mathrm{min}{ }^{-1}$ under a nitrogen flow of $100 \mathrm{ml} / \mathrm{min}$. From 
the first derivative of the curves, weight loss with respect to time and temperatures of maximum rate of weight loss were determined.

Catalyst recovery: After completion of reaction, the entire pitch was separated into two parts, i.e., upper and lower, which establish the heterogeneity of the system. The highdensity catalysts were settled down in the form of blackcolored solid mass in the lower part of glass reactor. For catalyst recovery from black-colored solid mass, refluxing is used with ethanol at $50{ }^{\circ} \mathrm{C}$. After refluxing, ethanol is separated from transition metal catalyst by distillation. However, in case of $\mathrm{Cr}$, above refluxed method is not used because $\mathrm{Cr}$ is insoluble in ethanol. So, there is a problem for recovery of this catalyst.

\section{Results and discussion}

\section{Analysis of mesophase pitch characteristics}

In our previous reported paper [9], paraffinic clarified oil (CLO) took a very large thermal soaking time $(21 \mathrm{~h})$ to convert into petroleum pitch at $370{ }^{\circ} \mathrm{C}$ having mesophase content below countable limit. In our previous paper, Co and Ni salts are used to improve mesophase content and optical texture of mesophase in CLO. But in the present work, we have used other transition metal salts, i.e., $\mathrm{Cr}$ and $\mathrm{Cu}$ salts in CLO to improve the mesophase content and optical texture of mesophase. The prepared pitches at $370{ }^{\circ} \mathrm{C}$ were ground and characterized by following procedures described in experimental section. The main physico-chemical properties of these pitches are summarized in Table 1. Pitches, i.e., CLO-Cr-3 and CLO-Cu-3, prepared from CLO using $\mathrm{Cr}$ and $\mathrm{Cu}$ catalysts, respectively, exhibit increased value of physico-chemical properties, i.e., softening point (SP), pitch yield (PY), coking value (CV), mesophase content (MC), toluene insolubles (TI) and quinoline insolubles (QI) as compared to CLO-0-0 pitch whose properties are reported in our previous paper [9]. $\mathrm{Cr}$ and $\mathrm{Cu}$ catalysts used in CLO for pitch preparation reduces the thermal soaking time to $4.20 \mathrm{~h}$ and $5.35 \mathrm{~h}$, respectively, as compared to base case CLO-0-0 (21 h) which is summarized in Table 1. Thermal soaking time is reduced because catalyst particles promote the polymerization and condensation reactions among the polycyclic aromatic molecules which lead to the gradual rise of SP, PY, CV, MC, TI and QI of the resultant mesophase products. These results were also consistent with the increase in $\mathrm{C} / \mathrm{H}$ ratios mentioned in Table 2 which indicated that dehydrogenative condensation reactions take place during thermal treatment process. Therefore, the above results revealed that $\mathrm{Cr}$ and $\mathrm{Cu}$ salts are effective for the growth of mesophase formation.
Table 2 Elemental analysis of pitches

\begin{tabular}{lccc}
\hline Sample & CLO-0-0 [9] & CLO-Cr-3 & CLO-Cu-3 \\
\hline C (wt \%) & 90.60 & 92.04 & 89.10 \\
H (wt \%) & 5.5 & 4.57 & 4.87 \\
N (wt \%) & 0.09 & 0.08 & 0.09 \\
S (wt \%) & 2.40 & 2.72 & 2.88 \\
C/H & 1.38 & 1.69 & 1.54 \\
\hline
\end{tabular}

Elemental analysis of pitches prepared from paraffinic CLO is summarized in Table 2. This analysis showed that all pitches are mainly composed of carbon, hydrogen, sulphur and least amount of nitrogen. Elemental analysis of CLO-Cr-3 and CLO-Cu-3 pitch samples showed a decrease in their hydrogen content along with increase of $\mathrm{C} / \mathrm{H}$ ratio (Table 2), which is 1.69 and 1.54 , respectively, as compared to CLO-0-0 (1.38). Therefore, these results revealed that $\mathrm{Cr}$ and $\mathrm{Cu}$ salts promote the dehydrogenation-type reactions in pitches which results in increasing $\mathrm{C} / \mathrm{H}$ ratio as compared to $\mathrm{CLO}-0-0$ pitch. Furthermore, more value of $\mathrm{C} / \mathrm{H}$ ratio indicates that polymerization and condensation reactions in mesophase pitches involved removal of hydrogen which results in the formation of highly aromatic molecules. Here, there is a possibility to some kind of interaction between Lewis acid catalysts, i.e., $\mathrm{Cr}$ and $\mathrm{Cu}$ and aromatic pitch molecule. The $\mathrm{CrCl}_{3}$ and $\mathrm{CuCl}_{2}$ also behave as weak Lewis acid. Thus, plausible mechanism involved in these interactions is similar to that of $\mathrm{FeCl}_{3}[8], \mathrm{AlCl}_{3}$ [29] and $\mathrm{HF} / \mathrm{BF}_{3}[23,25]$.

\section{Optical microscopic analysis of pitches}

Mesophase development during thermal treatment of paraffinic CLO using transition metal salts $(\mathrm{Cr}$ and $\mathrm{Cu})$ at $370{ }^{\circ} \mathrm{C}$ is tailored by plane-polarized light optical microscope which is shown in Fig. 2. In our previous reported paper [9], pitch CLO-0-0 exhibits mesophase content below countable limit (BCL), i.e., no mesophase spheres appear after a very long thermal treatment time $(21 \mathrm{~h})$. The use of $\mathrm{Cr}$ salt in CLO formed CLO-Cr-3 pitch which developed 9 vol \% of mesophase shown in Fig. 2. Optical microscopic image of CLO-Cr-3 exhibits large-size mesophase spheres along with tiny mesophase spheres which are heterogeneous in nature. Under the same experimental conditions, CLO$\mathrm{Cu}-3$ developed 12 vol \% of mesophase which is shown in Fig. 2. CLO-Cu-3 also exhibits very large-sized mesophase spheres which are also heterogeneous in nature. There are no significant differences in mesophase formation among two pitches prepared using $\mathrm{Cr}$ and $\mathrm{Cu}$ salts. Both pitches exhibit large-sized good optical texture of mesophase spheres which are heterogeneous in nature as compared to that of CLO-0-0 pitch having mesophase contents below countable limit. The plausible reason is that CLO-0-0 contains less naphthenic 

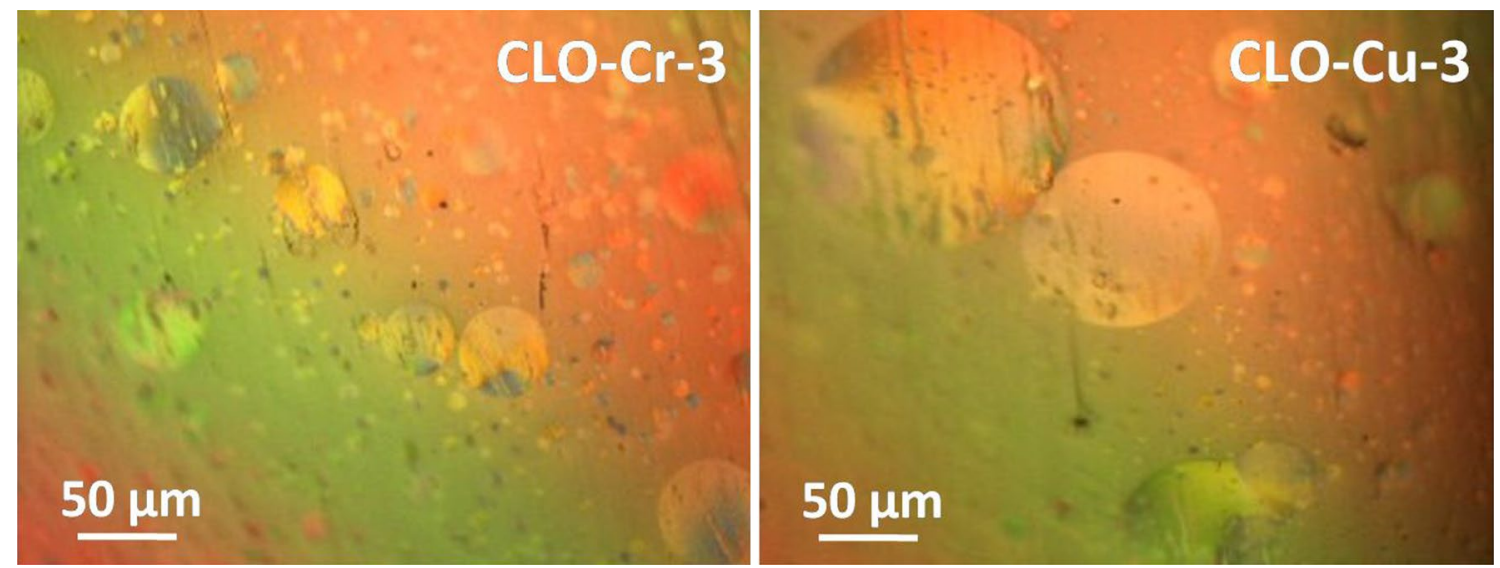

Fig. 2 Optical microscopic images of synthesized petroleum pitches

groups and more alkyl side chains, while CLO-Cr-3 and $\mathrm{CLO}-\mathrm{Cu}-3$ have more naphthenic groups and less alkyl side chains. Moreover, the alkyl side chains of CLO-Cr-3 and CLO-Cu-3 are shorter than that of CLO-0-0. The alkyl side chains of CLO-0-0 can be disintegrated rapidly to produce free radicals, which increase the polymerization reaction and also rapidly increase the viscosity of the whole system $[5,27]$. As a result, the development and coalescence of mesophase spheres are restricted. Therefore, in CLO-0-0, mesophase spheres do not appear. However, CLO-Cr-3 and $\mathrm{CLO}-\mathrm{Cu}-3$ contain more naphthenic groups which lead to hydrogen transfer reaction during the pyrolysis process and maintain low viscosity of the pitch. Then, large amount of tiny mesophase spheres are coalesce with each other to form large-size optical texture of mesophase pitch. Therefore, the results presented above showed that $\mathrm{Cr}$ and $\mathrm{Cu}$ accelerate the mesophase formation growth in CLO due to faster polymerization and condensation reactions.

\section{SEM and EDX analyses of mesophase pitches}

The surface images of petroleum pitches are taken by SEM and are presented in Fig. 3. Figure 3 shows that both pitches have flake-like structure along with fractured surfaces. SEM images of CLO-Cr-3 and CLO-Cu-3 have more flakes as compared to CLO-0-0 pitch because $\mathrm{Cr}$ and $\mathrm{Cu}$ facilitate that various hydrocarbons are polymerized to different extent and at a faster rate. Generally, the fracture structure is formed when a large amount of volatiles is released which changes the sample into solid product by fast increase in the viscosity of the system. Reported literature also mentioned that mesophase pitches have flake-like structure along with fractured surfaces [2, 33]. The EDX analyses (Fig. 3) show that petroleum pitches are mainly composed of carbon, nitrogen, oxygen and sulphur elements. The aluminium and chlorine elements are present in trace amount which may be come from mineral matter present in the petroleum feed stock. SEM and EDX analyses clearly show that catalyst particles are not attached to the surface of mesophase pitches which indicate that catalysts react with aromatic pitch molecules and promote the rate of chemical reactions but they do not mix with pitch molecules and settled down in the bottom of the reactor.

\section{FT-IR analysis}

FT-IR spectra of two different pitches prepared from CLO using transition metal salts $(\mathrm{Cr}$ and $\mathrm{Cu})$ are presented in Fig. 4. Figure 4 clearly shows that both pitches exhibit approximately same intensity and same absorption bands at nearly about the same positions. The spectra of these pitches mainly exhibit absorption bands corresponding to aromatic and aliphatic structures. The aromatic absorption bands observed at $3050 \mathrm{~cm}^{-1}$ due to aromatic $\mathrm{C}-\mathrm{H}$ stretching, at $1600 \mathrm{~cm}^{-1}$ due to aromatic $\mathrm{C}=\mathrm{C}$ stretching and at 870,810 and $745 \mathrm{~cm}^{-1}$ due to aromatic C-H out-of-plane bending vibrations $[17,26]$ which indicate the condensation degrees of polycyclic aromatic hydrocarbons. The aliphatic absorption bands observed at $2920 \mathrm{~cm}^{-1}$ due to aliphatic $\mathrm{C}-\mathrm{H}$ stretching and at $1440 \mathrm{~cm}^{-1}$ due to methylene $\mathrm{C}-\mathrm{H}$ in-plane bending vibrations $[17,26]$ indicate that a certain amount of aliphatic side chains are present in the mesophase pitch. FT-IR spectroscopy is also a useful technique to calculate aromaticity index of two different pitches by taking absorbance value at $3050 \mathrm{~cm}^{-1}$ and $2920 \mathrm{~cm}^{-1}$. The aromaticity index of pitches was calculated by following equation $I_{\mathrm{ar}}=\mathrm{Abs}_{3050} /\left(\mathrm{Abs}_{3050}+\mathrm{Abs}_{2920}\right)[10,12]$ which is presented in Fig. 4. The aromaticity index of CLO-Cr-3 and CLO$\mathrm{Cu}-3$ was evaluated to be 0.43 and 0.40 , respectively. The above result is also correlated with mesophase content of the pitches. As the aromaticity index of the pitches increases, mesophase content (Table 1) of the pitches also increases 


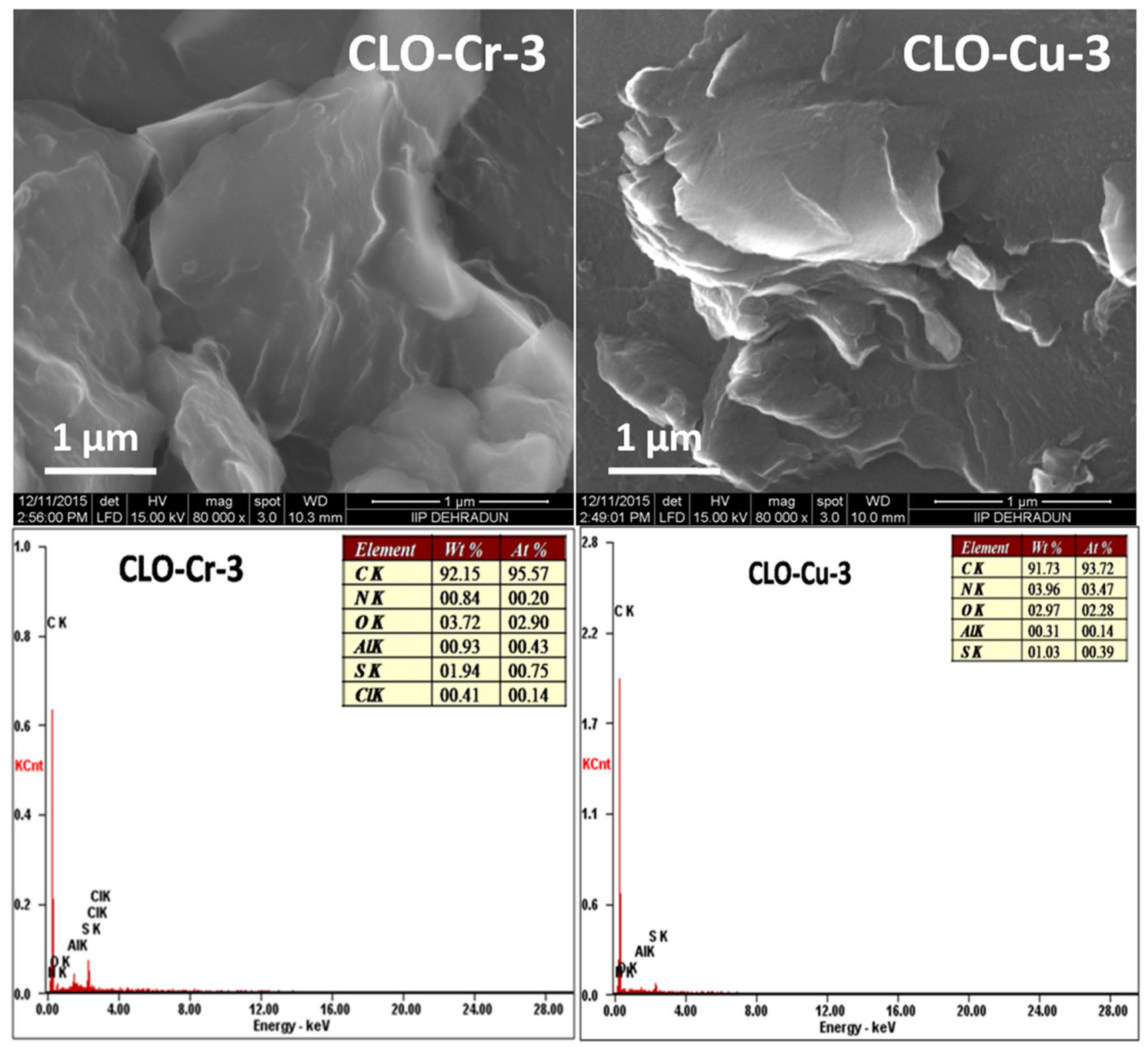

Fig. 3 SEM and EDX images of synthesize petroleum pitches

which result in the formation of large aromatic molecules by polymerization and condensation reactions. The results of the aromaticity index of pitches calculated by FT-IR are also consistent with the $\mathrm{C} / \mathrm{H}$ ratios (aromaticity calculated by CHNS analysis which is mentioned in Table 2).

\section{${ }^{1} \mathrm{H}$ NMR and ${ }^{13} \mathrm{C}$ NMR analyses}

${ }^{1} \mathrm{H}$ NMR and ${ }^{13} \mathrm{C}$ NMR spectroscopy is the most useful technique for investigating the composition of petroleumderived products, especially mesophase pitches. In this study, we have used this spectroscopy which brought the significant information about percentage distribution of 'aliphatic' and 'aromatic' protons and carbons, respectively, in both pitch samples. Integration regions used for ${ }^{1} \mathrm{H}$ NMR spectra were $0.5-4.5 \mathrm{ppm}$ for aliphatic protons $\left(\mathrm{H}_{\mathrm{al}}\right), 6-9 \mathrm{ppm}$ for aromatic protons $\left(\mathrm{H}_{\mathrm{ar}}\right)$; for ${ }^{13} \mathrm{C} \mathrm{NMR}$ spectra 5-50 ppm for saturated carbon $\left(\mathrm{C}_{\mathrm{sat}}\right), 100-160 \mathrm{ppm}$ for aromatic carbons $\left(\mathrm{C}_{\mathrm{ar}}\right)$ [11]. ${ }^{1} \mathrm{H}$ NMR spectral regions were subdivided according to the different types of hydrogen present in the pitch samples, as shown in Table 3. The normalized integration data of the different spectral regions of pitch samples are listed in Table 3 and their spectra are given in Fig. 5. ${ }^{1} \mathrm{H}$ NMR spectroscopy shows that CLO$\mathrm{Cr}-3$ and $\mathrm{CLO}-\mathrm{Cu}-3$ pitches have more aromatic hydrogen contents $\left(\mathrm{H}_{\mathrm{ar}}\right)$ and lower aliphatic hydrogen contents $\left(\mathrm{H}_{\mathrm{al}}\right)$ 

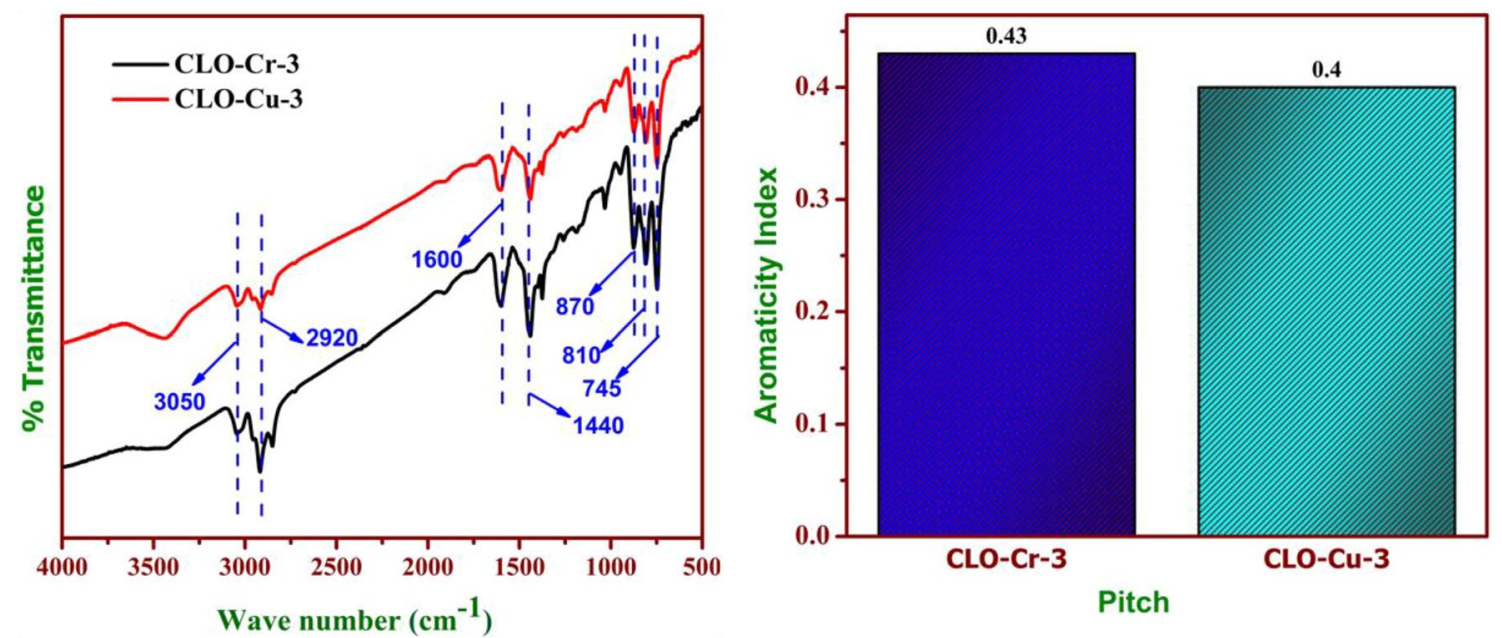

Fig. 4 FT-IR spectra and aromaticity index of synthesized petroleum pitches

Table 3 Normalized integration data based on the ${ }^{1} \mathrm{H}$ NMR and ${ }^{13} \mathrm{C}$ NMR spectra of pitches

\begin{tabular}{llrrr}
\hline & $\begin{array}{l}\text { Chemical } \\
\text { shift range } \\
(\mathrm{ppm})\end{array}$ & CLO-0-0 [9] & CLO-Cr-3 & CLO-Cu-3 \\
& & & & \\
\hline${ }^{1} \mathrm{H}$ NMR & & & & \\
$\mathrm{H}_{\mathrm{ar}(\mathrm{mono})}(\%)$ & $6.0-7.1$ & 5.20 & 5.96 & 5.26 \\
$\mathrm{H}_{\mathrm{ar}(\mathrm{di})}(\%)$ & $7.1-8.2$ & 42.86 & 70.86 & 49.17 \\
$\mathrm{H}_{\mathrm{ar}(\mathrm{poly})}(\%)$ & $8.2-9.0$ & 6.49 & 3.46 & 14.09 \\
$\mathrm{H}_{\mathrm{ar}} \%$ & $6.0-9.0$ & 54.55 & 80.27 & 68.52 \\
$\mathrm{H}_{\alpha} \%$ & $2.1-4.5$ & 26.87 & 10.63 & 27.16 \\
$\mathrm{H}_{\beta} \%$ & $1.1-2.1$ & 16.39 & 7.95 & 4.07 \\
$\mathrm{H}_{\gamma} \%$ & $0.5-1.1$ & 2.19 & 1.14 & 0.25 \\
$\mathrm{H}_{\mathrm{al}} \%$ & $0.5-4.5$ & 45.45 & 19.72 & 31.48 \\
$\mathrm{H}_{\mathrm{ar}} / \mathrm{H}_{\mathrm{al}}$ & - & 1.20 & 4.07 & 2.18 \\
${ }^{13} \mathrm{C} \mathrm{NMR}_{\mathrm{NM}}$ & & & & \\
$\mathrm{C}_{\mathrm{sat}} \%$ & $5-50$ & 11.57 & 8.29 & 9.90 \\
$\mathrm{C}_{\mathrm{ar}} \%$ & $100-160$ & 88.43 & 91.71 & 90.10 \\
$\mathrm{C}_{\mathrm{ar}} / \mathrm{C}_{\mathrm{sat}}$ & - & 7.64 & 11.06 & 9.10 \\
\hline
\end{tabular}

as compared to CLO-0-0 pitch because $\mathrm{Cr}$ and $\mathrm{Cu}$ catalysts promote the greater extent of 'polymerization' and 'condensation' reactions which are responsible for formation of parallely stacked planar aromatics in mesophase pitches. Furthermore, the aromatic hydrogen $\left(\mathrm{H}_{\mathrm{ar}}\right)$ contents of both the resultant pitches increase, and simultaneously aliphatic hydrogen $\left(\mathrm{H}_{\mathrm{al}}\right)$ deceases, which also suggest that cracking or dehydrogenative aromatization process of the aliphatic side chains occurs during the thermal polymerization $[7$, 32]. In general, both pitches have more $\alpha$ proton $\left(\mathrm{H}_{\alpha}\right)$ as compared to $\beta$ protons $\left(\mathrm{H}_{\beta}\right)$ and $\gamma$ protons $\left(\mathrm{H}_{\gamma}\right)$ which means that most of the alkyl groups linked to the aromatic rings are $\alpha$-methylene which facilitates the cracking reactions during the thermal soaking. These cracking reaction forms the benzylic-type free radical, which then polymerized to form parallely stacked planar aromatic bridge structures. Furthermore, if the pitches contained large amount of long alkyl side chains and alkyl substituents, then it would generate more free radicals, which make the polymerization and condensation reaction very fast and restrict the growth of mesophase spheres and giving low softening point pitches [5, 31]. Therefore, pitch molecules should contain a certain number of naphthenic groups and short alkyl side chains to get a good-quality mesophase pitch having high softening point and also exhibit better optical texture of mesophase. Also, the hydrogen aromaticity index $\left(\mathrm{H}_{\mathrm{ar}} / \mathrm{H}_{\mathrm{al}}\right)$ of prepared pitches follows the trend CLO-Cr-3 > CLO-Cu-3 > CLO-0-0 which also suggest that $\mathrm{Cr}$ and $\mathrm{Cu}$ enhances the polymerization/condensation reactions during the thermal soaking occur at the expense of aliphatic hydrogen. Like ${ }^{1} \mathrm{H}$ NMR spectra, ${ }^{13} \mathrm{C}$ NMR spectroscopy also supports the above findings of pitches whose integration data are listed in Table 3. The effect of $\mathrm{Cr}$ and $\mathrm{Cu}$ catalysts on hydrogen $\left(\mathrm{H}_{\mathrm{ar}} / \mathrm{H}_{\mathrm{al}}\right)$ and carbon aromaticity $\left(\mathrm{C}_{\mathrm{ar}} / \mathrm{C}_{\mathrm{sat}}\right)$ is similar to that observed for aromaticity (C/H ratio Table 2, $I_{\text {ar }}$ by FT-IR in Fig. 4).

\section{XRD analysis of mesophase pitches}

XRD of CLO-Cr-3 and CLO-Cu-3 pitches prepared from CLO using transition metal catalysts is shown in Fig. 6. As seen in the figure, the diffractogram of CLO-Cr-3 and CLO$\mathrm{Cu}-3$ shows two broad peaks at approximately $25.5^{\circ}$ and $45^{\circ}$, which corresponds to the graphite-like carbon material. First peak at $25.5^{\circ}$ is a strong peak which indicates that pitches primarily had (002) crystal planes corresponding to carbon structures due to the stacking of aromatic layers and at $45^{\circ}$, weak broad peak appears which corresponds to pitches that

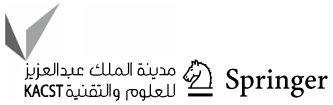



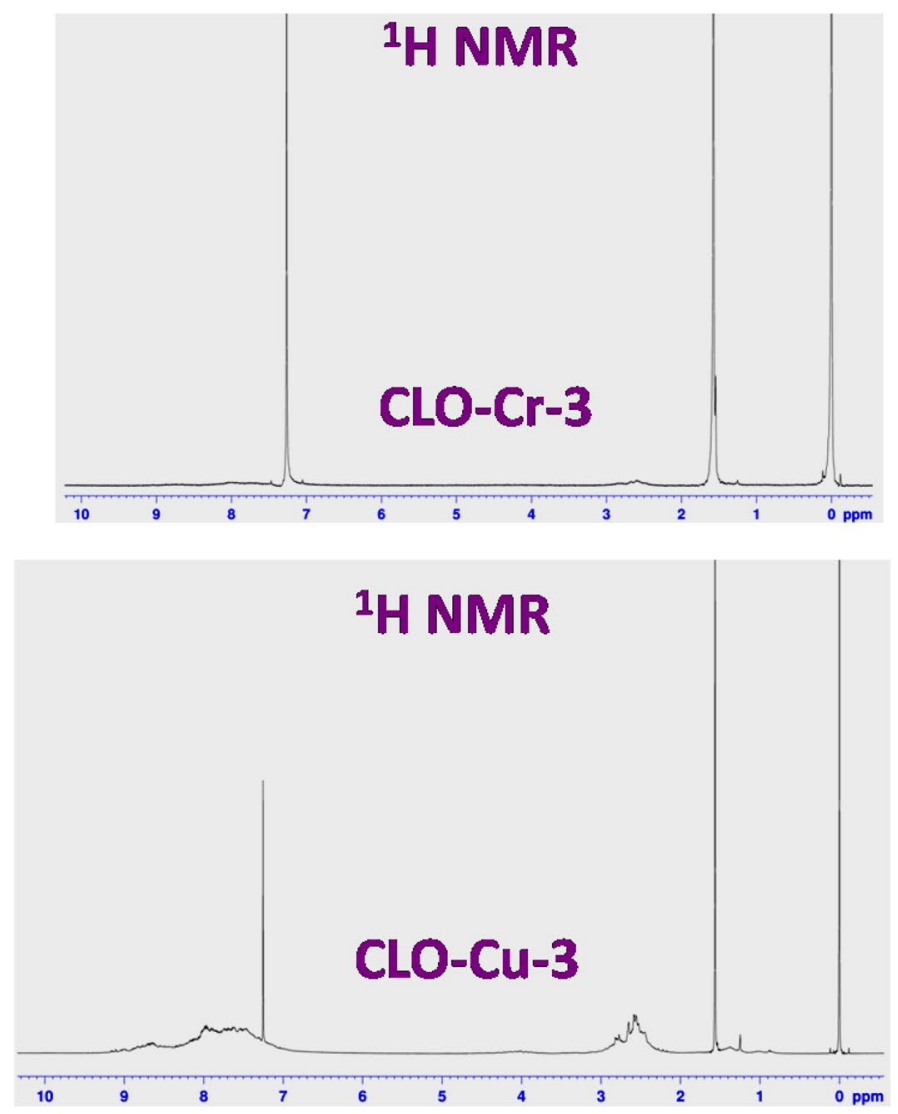

\section{${ }^{13}$ C NMR}

\section{$\mathrm{CLO}-\mathrm{Cr}-3$}

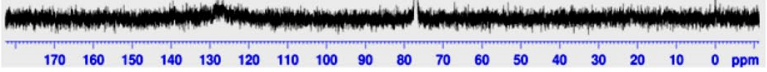

${ }^{13}$ C NMR

\section{$\mathrm{CLO}-\mathrm{Cu}-3$}

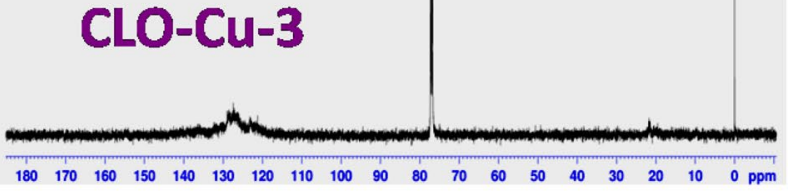

Fig. $5{ }^{1} \mathrm{H}$ NMR and ${ }^{13} \mathrm{C}$ NMR spectra of synthesized petroleum pitches

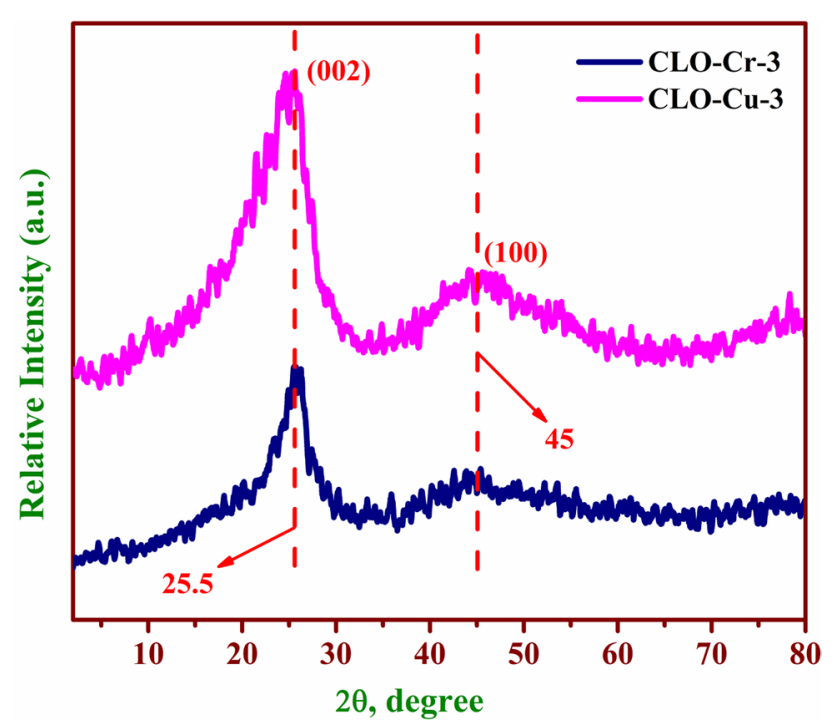

Fig. 6 X-ray diffractograms of synthesized petroleum pitches

partially had (100) crystal planes. These two peaks (002) and (100) are assigned to amorphous carbon. Other parameters such as crystallite thickness $\left(L_{\mathrm{c}}\right)$, interlayer spacing $\left(d_{002}\right)$, number of aromatic sheet stacked in cluster $(N)$ and average
Table 4 X-ray diffraction parameters of pitches

\begin{tabular}{llll}
\hline Sample & CLO-0-0 [9] & CLO-Cr-3 & CLO-Cu-3 \\
\hline $\mathrm{L}_{\mathrm{c}}(\AA)$ & 9.85 & 17.97 & 15.51 \\
$d_{002}(\AA)$ & 3.636 & 3.443 & 3.523 \\
$N^{\mathrm{a}}$ & 3 & 6 & 5 \\
$n^{\mathrm{b}}$ & 3 & 12 & 8 \\
\hline
\end{tabular}

${ }^{\mathrm{a}} N=L_{\mathrm{c}} / d_{002}+1$ where $N$ is ordered stacking number

${ }^{\mathrm{b}}$ Average number of carbon atom per lamellae $(n)$ where $n=0.32 N^{2}$

number of carbon atom per lamellae $(n)$ are also calculated from these diffractograms listed in Table 4 . The crystallite thickness $\left(L_{\mathrm{c}}\right)$, number of aromatic sheet stacked in cluster $(N)$ and average number of carbon atom per lamellae $(n)$ are found to be varying from 15.51 to $17.97,5$ to 6 and 8 to 12 , respectively, for pitch samples. Table 4 shows that $L_{\mathrm{c}}, N$ and $n$ values of CLO-Cr-3 and CLO-Cu-3 pitches are increased together with a decrease in their interlayer distance $\left(d_{002}\right)$ as compared to CLO-0-0 pitch whose parameters are reported in our previous paper [9]. The increased value of $L_{\mathrm{c}}, N$ and $n$ indicates that transition metal salts $(\mathrm{Cr}$ and $\mathrm{Cu})$ promote the polymerization and condensation reactions in paraffinic CLO which result in the formation of parallely 
stacked planar aromatic molecules, i.e., mesophase molecules. Furthermore, in XRD, no extra peaks of $\mathrm{Cr}$ and $\mathrm{Cu}$ were observed in pitches which show that these transition metal salts do not attach with pitch molecule. These results are also consistent with SEM-EDX spectra results. Further, $L_{c}$ and $N$ trends from the XRD analysis correspond to the $\mathrm{C} / \mathrm{H}$ ratios (Table 2) and $I_{\mathrm{ar}}$ (Fig. 4) related to the aromatic contents.

\section{TGA analysis of mesophase pitches}

The thermal decomposition properties of synthesized petroleum pitches were probed over the temperature range of $40-900{ }^{\circ} \mathrm{C}$ which is shown in Fig. 7. Figure 7 explicitly shows that $\mathrm{CLO}-\mathrm{Cu}-3$ and $\mathrm{CLO}-\mathrm{Cr}-3$ petroleum pitches exhibited higher thermal stability than CLO-0-0 petroleum pitch. The higher thermal stability of CLO-Cu-3 and CLO$\mathrm{Cr}-3$ petroleum pitches is due to the presence of aromatic rings in their complex polynuclear aromatic structure. It was noted that all petroleum pitches thermally decomposed in the range of $210-550{ }^{\circ} \mathrm{C}$. Temperature of initial weight loss $\left(T_{\mathrm{i}}\right)$, temperature of final weight loss $\left(T_{\mathrm{f}}\right)$, and temperature of maximum rate of weight loss $\left(T_{\max }\right)$ calculated from TG/DTG curves are shown in Fig. 7 and Table 5. The initial weight loss can be ascribed to the distillation of low-molecular weight hydrocarbons, while the final weight loss may be due to the removable of light hydrocarbon molecules from the pitch samples which are cracked during pyrolysis. DTG curves show that temperature of maximum rate of weight loss of both $\mathrm{CLO}-\mathrm{Cu}-3$ and CLO-Cr-3 pitches occurred between 300 and $350{ }^{\circ} \mathrm{C}$ approximately which indicates that complex polycyclic aromatic hydrocarbons are present in it. Table 5 shows
Table 5 TG and DTG parameters of pitch samples

\begin{tabular}{llll}
\hline Sample & CLO-0-0 [9] & CLO-Cr-3 & CLO-Cu-3 \\
\hline TG/DTG $\left({ }^{\circ} \mathrm{C}\right)$ & & & \\
$T_{\mathrm{i}}^{\mathrm{a}}$ & 185 & 199 & 215 \\
$T_{\mathrm{f}}^{\mathrm{b}}$ & 480 & 530 & 538 \\
$T_{\max }^{\mathrm{c}}$ & 347 & 308 & 342 \\
$\mathrm{M}^{\mathrm{d}}$ & 70.02 & 44.39 & 58.10 \\
$\mathrm{CY}^{\mathrm{e}}$ & 29.98 & 55.61 & 41.90 \\
\hline
\end{tabular}

${ }^{\text {a }}$ Temperature of initial weight loss $\left({ }^{\circ} \mathrm{C}\right)$

${ }^{\mathrm{b}}$ Temperature of final weight loss $\left({ }^{\circ} \mathrm{C}\right)$

${ }^{\mathrm{c}}$ Temperature of maximum weight loss rate $\left({ }^{\circ} \mathrm{C}\right)$

${ }^{\mathrm{d}}$ Mass lose (wt \%)

${ }^{\mathrm{e}}$ Carbonization yield at $900{ }^{\circ} \mathrm{C}$ (wt \%) (carbonization yield $=100$ - weight loss of mesophase pitch)

that in the temperature range of $40-900{ }^{\circ} \mathrm{C}, \mathrm{CLO}-\mathrm{Cr}-3$ and CLO-Cu-3 pitches lost 44.39 and $58.10 \mathrm{wt} \%$ of their original mass. The weight loss of both the pitch samples was ceased at approximately $550{ }^{\circ} \mathrm{C}$. The flat pattern of the TG curve over $550{ }^{\circ} \mathrm{C}$ corresponds to coke formation [3]. In addition, we can also calculate carbonization yield of pitch samples from TGA curve (Fig. 7) which is listed in Table 5. Carbonization yield obtained from TGA curves at $900{ }^{\circ} \mathrm{C}$ showed that $\mathrm{CLO}-\mathrm{Cr}-3$ and $\mathrm{CLO}-\mathrm{Cu}-3$ pitches have more carbon residue yield as compared to CLO-0-0 pitch which suggested that catalyst promotes the polymerization and condensation reactions which result in the formation of more complex polycyclic aromatic hydrocarbons. Furthermore, this finding indicates that copper and chromium catalysts facilitate more polymerization and condensation reaction during thermal soaking of pitch formation.
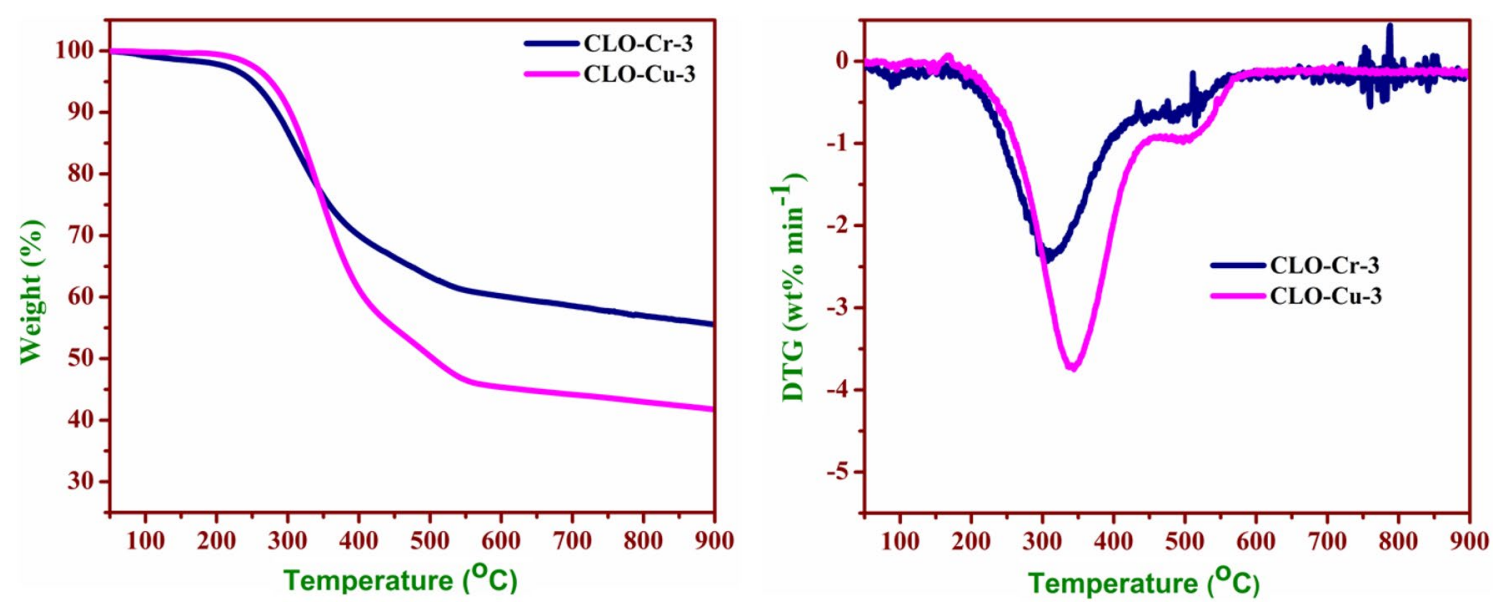

Fig. 7 Thermogravimetric (left) and derivative thermogravimetric (right) curve of synthesized petroleum pitches

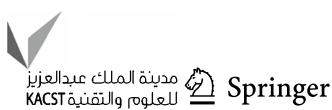




\section{Conclusions}

The focus of this work was to synthesize petroleum mesophase pitches from paraffinic clarified oil by transition metal catalysts (i.e., $\mathrm{Cr}$ and $\mathrm{Cu}$ ) as precursor material for advanced carbon products and also study the effect of these catalysts on physico-chemical properties. Generally, paraffinic hydrocarbons are undesirable for making mesophase pitches but their attachments on aromatic molecules are necessary because they generate free radicals for polymerization reaction. Optical microscopic results show that $\mathrm{Cu}$ and $\mathrm{Cr}$ enhance the growth of mesophase spheres and also increase the mesophase contents. Therefore, $\mathrm{Cu}$ and $\mathrm{Cr}$ promote the parallely stacked aromatic mesophase formation in pitches through a series of reactions such as cracking, polymerization, condensation, etc. The higher value of crystallite thickness of CLO-Cu-3 and CLO-Cr-3 as compared to CLO-0-0 also indicates that there is a high degree of polymerization. NMR, FT-IR and CHNS analyses also support the higher degree of polymerization for CLO-Cu-3 and CLO-Cr-3 mesophase pitches. In addition, SEM images clearly indicated that catalysts increase the size of pitch flakes but they are not attached on the surface of pitch molecules. Therefore, the present study shows that $\mathrm{Cu}$ and $\mathrm{Cr}$ catalysts have higher catalytic activity for mesophase formation growth. It was further observed that $\mathrm{Cu}$ and $\mathrm{Cr}$ catalysts are also helpful for increasing physico-chemical properties of mesophase pitches.

Acknowledgements We kindly acknowledge the Director IIP for his kind permission to publish these results. We are also thankful to Analytical Science Division at IIP for analysis of the samples. Author SK thanks UGC for awarding fellowship.

Open Access This article is distributed under the terms of the Creative Commons Attribution 4.0 International License (http://creativeco mmons.org/licenses/by/4.0/), which permits unrestricted use, distribution, and reproduction in any medium, provided you give appropriate credit to the original author(s) and the source, provide a link to the Creative Commons license, and indicate if changes were made.

\section{References}

1. Albero AS, Fernandez JMR, Escandell MM, Escribano AS, Albero JS, Reinoso FR (2010) High saturation capacity of activated carbons prepared from mesophase pitch in the removal of volatile organic compounds. Carbon 48:548-556

2. Chun-yu G, Cheng-yang W (2007) Effect of microstructure of precursors on characteristics of pitch based activated carbons. Microporous Mesoporous Mater 102:337-340

3. Dumont M, Chollon G, Dourges MA, Pailler R, Bourrat X, Naslain R, Bruneel JL, Couzi M (2002) Chemical, microstructural and thermal analyses of a naphthalene-derived mesophase pitch. Carbon 40:1475-1486
4. Fernadez AL, Granda M, Bermejo J, Menendez R (1999) Catalytic polymerization of anthracene oil with aluminium trichloride. Carbon 37:1247-1255

5. Fortin F, Yoon SH, Korai Y, Mochida I (1994) Reorganization of molecular alignment in naphthalene and Methylnaphthalene derived pitches. Carbon 32:979-989

6. Greinke RA, Lewis IC (1984) Carbonization of naphthalene and dimethylnaphthalene. Carbon 22:305-314

7. Herndon WC (1982) Thermal reactivities of polynuclear aromatic hydrocarbons and alkyl derivatives. Tetrahedron 38:1389-1396

8. Kovacic P, Koch FW (1965) Coupling of naphthalene nuclei by Lewis acid catalyst—oxidant. J Org Chem 30:3176-3181

9. Kumar S, Srivastava M (2015) Catalyzing mesophase formation by transition metals. J Anal Appl Pyrolysis 112:192-200

10. Kumar S, Srivastava M (2015) Mesophase formation behavior in petroleum residues. Carbon Lett 16:171-182

11. Kumar S, Srivastava M (2016) Influence of presence/addition of asphaltenes on semi-coke textures and mesophase development in petroleum feed stocks. Fuel 173:69-78

12. Kumar S, Srivastava M (2017) Meliorate optical textures and mesophase contents by promising approach of deasphalting of petroleum residues. J Ind Eng Chem 48:133-141

13. Lewis IC (1980) Thermal polymerization of aromatic hydrocarbons. Carbon 18:191-196

14. Liu H, Li T, Shi Y, Wang X, Lv J, Zhang W (2014) Effect of different secondary quinoline insoluble content on the cellular structure of carbon foam derived from coal tar pitch. J Anal Appl Pyrolysis 108:310-315

15. Manoj B, Kunjomana AG (2012) Study of stacking structure of amorphous carbon by X-ray diffraction technique. Int J Electrochem Sci 7:3127-3134

16. Mendez A, Santamaria R, Granda M, Menendez R (2008) Structural changes during pitch-based carbon granular composites carbonisation. J Mater Sci 43:906-921

17. Miyajima N, Akatsu T, Ikoma T, Ito O, Rand B, Tanabe Y (2000) A role of charge-transfer complex with iodine in the modification of coal tar pitch. Carbon 38:1831-1838

18. Mochida I, Nakamura EI, Maeda K, Takeshita K (1975) Carbonization of aromatic hydrocarbons-III: carbonization catalyzed by alkali metals. Carbon 13:489-493

19. Mochida I, Kudo K, Fukuda N, Takeshita K (1975) Carbonization of pitches-IV: carbonization of polycyclic aromatic hydrocarbons under the presence of aluminium chloride catalyst. Carbon 13:135-139

20. Mochida I, Nakamura EI, Maeda K, Takeshita K (1976) Carbonization of aromatic hydrocarbons-IV: reaction path of carbonization catalyzed by alkali metals. Carbon 14:123-129

21. Mochida I, Inoue SI, Maeda K, Takeshita K (1977) Carbonization of aromatic hydrocarbons-VI: carbonization of heterocyclic compounds catalyzed by aluminium chloride. Carbon 15:9-16

22. Mochida I, Sone Y, Korai Y (1985) Preparation and properties of carbonaceous mesophase-II highly soluble mesophase from ethylene tar modified using aluminum chloride as a catalyst. Carbon 23:175-178

23. Mochida I, Shimizu K, Korai Y, Otsuka H, Fujiyama S (1988) Structure and carbonization properties of pitches produced catalytically from aromatic hydrocarbons with $\mathrm{HF} / \mathrm{BF}_{3}$. Carbon 26:843-852

24. Mochida I, Fei YQ, Korai Y, Oishi T (1990) Co-carbonization of ethylene tar pitch and coal tar pitch to form needle coke. Fuel 69:672-677

25. Mochida I, Shimizu K, Korai Y (1990) Preparation of mesophase pitch from aromatic hydrocarbons by the aid of $\mathrm{HF} / \mathrm{BF}_{3}$. Carbon 28:311-319 
26. Mochida I, Shimizu K, Korai Y, Sakai Y, Fujiyama S, Toshima H, Hono T (1992) Mesophase pitch catalytically prepared from anthracene with $\mathrm{HF} / \mathrm{BF}_{3}$. Carbon 30:55-61

27. Qian SA, Xiao YX, Gu YD (1987) Study on chemical composition and formation mechanism of some typical pitch feedstocks using field desorption mass spectrometry. Fuel 66:242-249

28. Rey Boero JF, Wargon JA (1981) Study of the $\mathrm{AlCl}_{3}$ catalytic activity on aromatic hydrocarbons-II: mesophase formation. Carbon 19:341-346

29. Rey Boero JF, Wargon JA (1981) Study of the $\mathrm{AlCl}_{3}$ catalytic activity on aromatic hydrocarbons-I: low temperature range. Carbon 19:333-340

30. Sharma A, Kyotani T, Tomita A (2000) Comparison of structural parameters of PF carbon from XRD and HRTEM techniques. Carbon 38:1977-1984

31. Shin S, Jang J, Yoon SH, Mochida I (1997) A study on the effect of heat treatment on functional groups of pitch based activated carbon fiber using FTIR. Carbon 35:1739-1743

32. Torregrosa-Rodriguez P, Martinez-Escandell M, RodriguezReinoso F, Marsh H, de Salazar CG, Palazon ER (2000) Pyrolysis of petroleum residues: II. Chemistry of pyrolysis. Carbon 38:535-546
33. Weishauptova Z, Medek J (1985) Pitch coke structure and its transition to graphite: influence of the separation process of quinolineinsoluble matter. Fuel 64:999-1006

34. Yang YS, Wang CY, Chen MM, Shi ZQ, Zheng JM (2010) Facile synthesis of mesophase pitch/exfoliated graphite nanoplatelets nanocomposite and its application as anode materials for lithiumion batteries. J Solid State Chem 183:2116-2120

35. Yang Y, Lin Q, Huang Y, Guo D (2011) Efficient preparation of mesocarbon microbeads by pyrolysis of coal-tar pitch in the presence of rosin. J Anal Appl Pyrolysis 91:310-315

36. Yao Y, Chen J, Liu L, Dong Y, Liu A (2012) Tailoring structures and properties of mesophase pitch-based carbon fibers based on isotropic/mesophase incompatible blends. J Mater Sci 47:5509-5516

Publisher's Note Springer Nature remains neutral with regard to jurisdictional claims in published maps and institutional affiliations. 